\title{
Transformation of sewed peat soils of the Western Polissya at long agricultural use
}

\author{
Yu. Tarariko, \\ Corresponding Member of the National Academy of Sciences of Ukraine, Doctor of Agricultural \\ L. Datsko, \\ Candidate of Agricultural Sciences \\ Institute of Water Problems and Land Reclamation of NAAS \\ M. Stetsiuk, \\ M. Zosymchuk, \\ Candidate of Agricultural Sciences \\ Sarnen Experimental Station of the Institute of Water Problems and Melioration of the National \\ Academy of Sciences of Ukraine
} Sciences

The purpose. To study direction of processes of transformation of sewed peat soils of the Western Polissya at inning and long agricultural use. Methods. Field, laboratory, analysis of variance. Results. Results of long-term researches in influence of long agricultural use on change of water-physical and agrochemical properties of peat soils of the Western Polissya are brought. Conclusions. It is determined that the period and intensity of agricultural use of peat soils influence change of their water-physical and agrochemical properties. So, for the long-term period of researches the density of soil on long pratums has increased in 1,58 times $(1958-0,210 \mathrm{~g} / \mathrm{cm} 3,2015-0,333 \mathrm{~g} / \mathrm{cm} 3$ ), and at intense agricultural use (draw through crop rotation) - in 2,1 times $(1958-0,210 \mathrm{~g} / \mathrm{cm} 3,2015-0,446 \mathrm{~g} / \mathrm{cm} 3)$. It is fixed that for more than 50 years of agricultural use peat soils from low- and average-ash were converted in high-ash.

Key words: sewed peat soils, transformation, water-physical properties, agrochemical properties.

Statement of the problem. Extensive work on the drainage of hydromorphic soils was aimed at increasing the production of gross output of agriculture. According to various estimates, now in Ukraine there are about 1 million hectares of drained peat soils $[2,6,8]$. Together, because of their specific water-physical and agrochemical properties of drained peat soils are very dynamic and readily undergo degradation (primarily intensive mineralization and deployment) $[1,3,4,5,7,10]$. As a result of drainage in the Ukraine over the past 3 decades there has been a decrease in peat resources 120-150 million tons a Negative balance in the transformation of organic matter peat soil annually up to 7-10 t/ha. On average in Polesie reduction of the peat layer, mostly through the seals is in the initial period of $10-35 \mathrm{~mm}$. $[1,6,8]$.

In the course of agricultural use change agrophysical indicators of organogenic soils, the change of water, air and nutrient regimes. This in turn leads to performance degradation of peat soils: the growth of nutrient deficiency, compaction, acidification, etc $[4,5,8,9]$. The aim of the research is to determine the direction of the transformation of drained peat soils during drainage and long-term agricultural use.

The methodology of the research. Sarny research station of Institute of water problems and land reclamation for many decades explores agro-ecological change of the drained peat soils under the influence of long agricultural use in conditions of Western Polissya. The changes in water-physical properties of drained peat soils was studied in long-term stationary field experiment Sarny experimental station in posing crop rotation and long-term meadows (grass 1955 sowing). The field experiment laid down in 1955-1956 year the General field and forage rotation.

The results of the research. Lengthy studies have found that for 57 years, the density of the arable layer of the soil under peat meadows long term use increased 1,52 times (before $0,2100,320 \mathrm{~g} / \mathrm{cm}^{3}$ ). Under intensive agricultural use in posing rotation during the same period of use, the density increased 1,86 times 
(before $0,2100,390 \mathrm{~g} / \mathrm{cm} 3$ ). In crop rotation with a 4-year field period (MP) was a relatively small seal peat drained soil, in which soil density increased to $1,67 \mathrm{~g}\left(0,210\right.$ to $\left.0,350 \mathrm{~g} / \mathrm{cm}^{3}\right)$. Introduction to crop rotation of 6 fields of perennial grasses insignificantly reduced seal peat drained soil 1,66 times (table. 1-2).

Constructing linear trends of the process of compaction during the whole time of its use in agricultural production (Fig. 1), it was found that the dynamics of the soil (increase its bulk density) to posing rotation occurred at an average speed of $30,8 \mathrm{mg} / \mathrm{cm}^{3}$ for 10 years. Introduction in the crop rotation 4-6 fields of perennial grasses have slowed the process down to $23,0-23,6$ per $\mathrm{mg} / \mathrm{cm}^{3}$ for 10 years. Under long-term grassland the process of compaction was slowed down to $20 \mathrm{mg} / \mathrm{cm}^{3}$ for 10 years. The obtained results will be useful for scientific justification when adopting decisions on the development of a system of crop rotation on drained organic soils when it is necessary to find a "middle ground" between economic and ecological expediency, that is, to obtain the maximum economic result and an acceptable environmental burden on the soil.

1. The influence of long-term agricultural use peat drained soil to change its density (arable layer 0 $30 \mathrm{~cm}, \mathrm{~g} / \mathrm{cm}^{3}$ )

\begin{tabular}{|l|c|c|c|c|c|c|c|c|}
\hline \multicolumn{1}{|c|}{ Rotation } & 1958 & 1974 & 1983 & 1993 & 2001 & 2007 & 2015 & $\begin{array}{c}\text { Second } \\
\text { ary }\end{array}$ \\
\hline Crop rotation & 0,210 & 0,280 & 0,290 & 0,310 & 0,356 & 0,368 & 0,390 & 0,315 \\
\hline $\begin{array}{l}\text { Rotation with a 4- } \\
\text { year meadow } \\
\text { period }\end{array}$ & 0,210 & 0,270 & 0,290 & 0,300 & 0,326 & 0,337 & 0,350 & 0,298 \\
\hline $\begin{array}{l}\text { Rotation with a 6- } \\
\text { year meadow } \\
\text { period }\end{array}$ & 0,210 & 0,280 & 0,290 & 0,300 & 0,329 & 0,338 & 0,349 & 0,299 \\
\hline Long-term meadow & 0,210 & 0,240 & 0,260 & 0,280 & 0,300 & 0,309 & 0,320 & 0,274 \\
\hline Secondary & 0,210 & 0,275 & 0,290 & 0,300 & 0,328 & 0,338 & 0,350 & \\
\hline
\end{tabular}

2. The dynamics of compaction of arable layer $(0-30 \mathrm{~cm})$ drained peat soil at various stages of the study $\left(\mathrm{mg} / \mathrm{cm}^{3} /\right.$ year $)$

\begin{tabular}{|c|c|c|c|c|c|c|c|}
\hline Rotation & $\begin{array}{r}1959 \\
-1974\end{array}$ & $\begin{array}{r}1975 \\
-1983\end{array}$ & $\begin{array}{r}1984 \\
-1993\end{array}$ & $\begin{array}{r}1994 \\
-2001\end{array}$ & $\begin{array}{r}2002 \\
-2007\end{array}$ & $\begin{array}{l}2008 \\
-2015\end{array}$ & $\begin{array}{l}\text { Seco } \\
\text { ndary }\end{array}$ \\
\hline Crop rotation & 4,38 & 1,11 & 2,00 & 5,75 & 2,00 & 2,75 & 3,00 \\
\hline $\begin{array}{l}\text { Rotation with a } 4 \text {-year } \\
\text { meadow period }\end{array}$ & 3,75 & 2,22 & 1,00 & 3,25 & 1,83 & 1,62 & 2,28 \\
\hline $\begin{array}{l}\text { Rotation with a 6-year } \\
\text { meadow period }\end{array}$ & 4,38 & 1,11 & 1,00 & 3,63 & 1,50 & 1,37 & 2,16 \\
\hline Long-term meadow & 1,88 & 2,22 & 2,00 & 2,50 & 1,50 & 1,38 & 1,91 \\
\hline
\end{tabular}




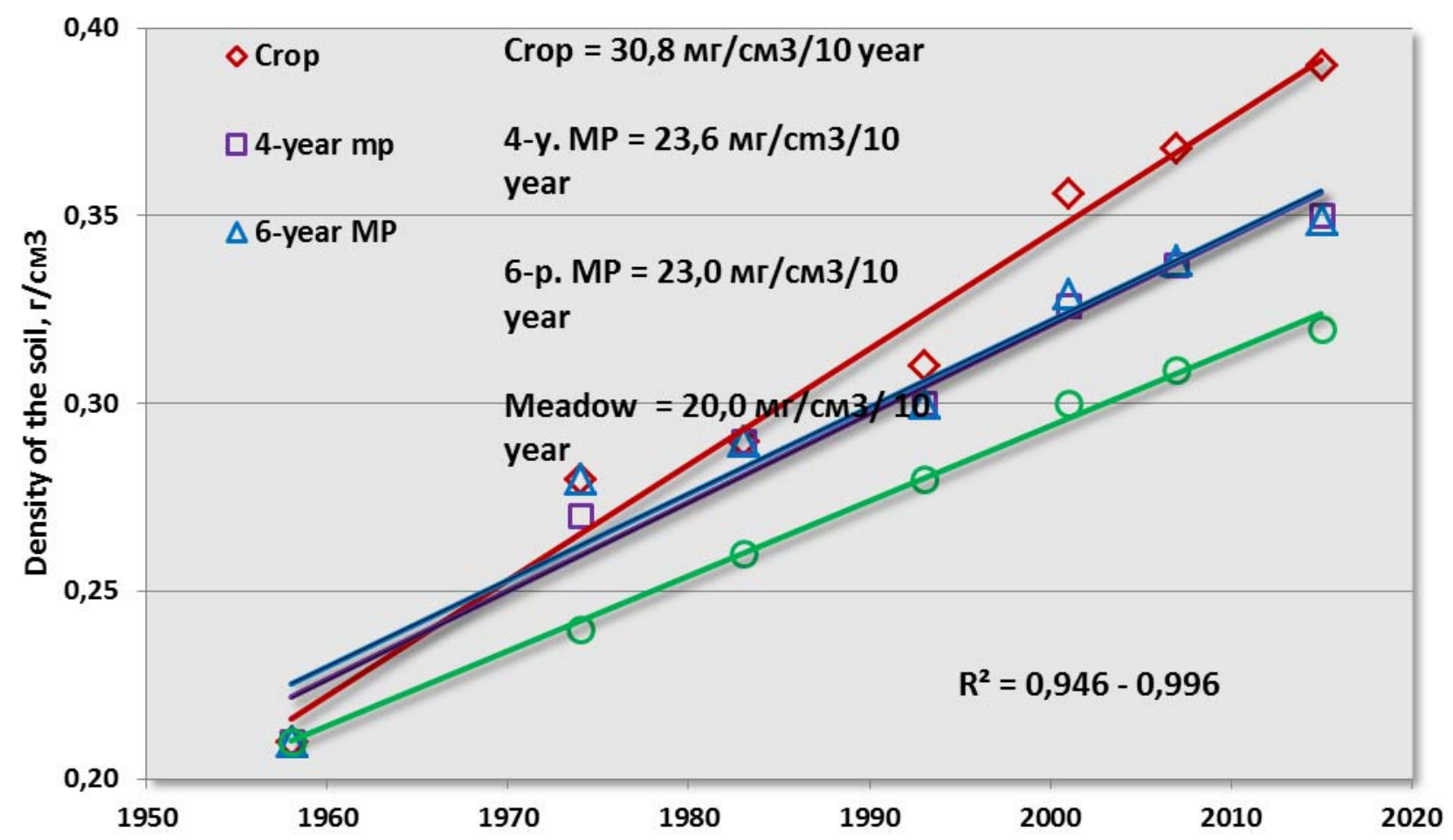

Fig 1. The dynamics of compaction of arable layer $(0-30 \mathrm{~cm})$ peat drained soil under the influence of long agricultural use (array "Chemerne" Sarny research station, 1958-2015.)

Examining factors that influence the processes of soil compaction under the action of its agricultural use is established, that in addition to intensity of anthropogenic load on the soil have an important influence also hydrothermal conditions warm (growing) period and, primarily soil moisture. It primarily depends on precipitation (Fig. 2).

A number of mathematical relationships that describe the growth rate of bulk density (compaction) of the arable layer of peat soil ( $\mathrm{Mv}, \mathrm{mg} / \mathrm{cm} 3 / \mathrm{year}$ ) for different use depending on the amount of precipitation during the vegetation period $(\mathrm{R}, \mathrm{mm})$ :

$\Delta \mathrm{Mv}$ (Crop rotation) $=-0,0003 \mathrm{R}^{2}+0,217 \mathrm{R}-34,44$;

$\Delta \mathrm{Mv}$ (Rotation with a 4-year MP) $=-0,0002 \mathrm{R}^{2}+0,117 \mathrm{R}-18,10$;

$\Delta \mathrm{Mv}$ (Rotation with a 6-year MP) $=-0,0002 \mathrm{R}^{2}+0,168 \mathrm{R}-26,91$;

$\Delta \mathrm{Mv}$ (Long-term meadow) $=0,003 \mathrm{R}^{2}+0,686$ 


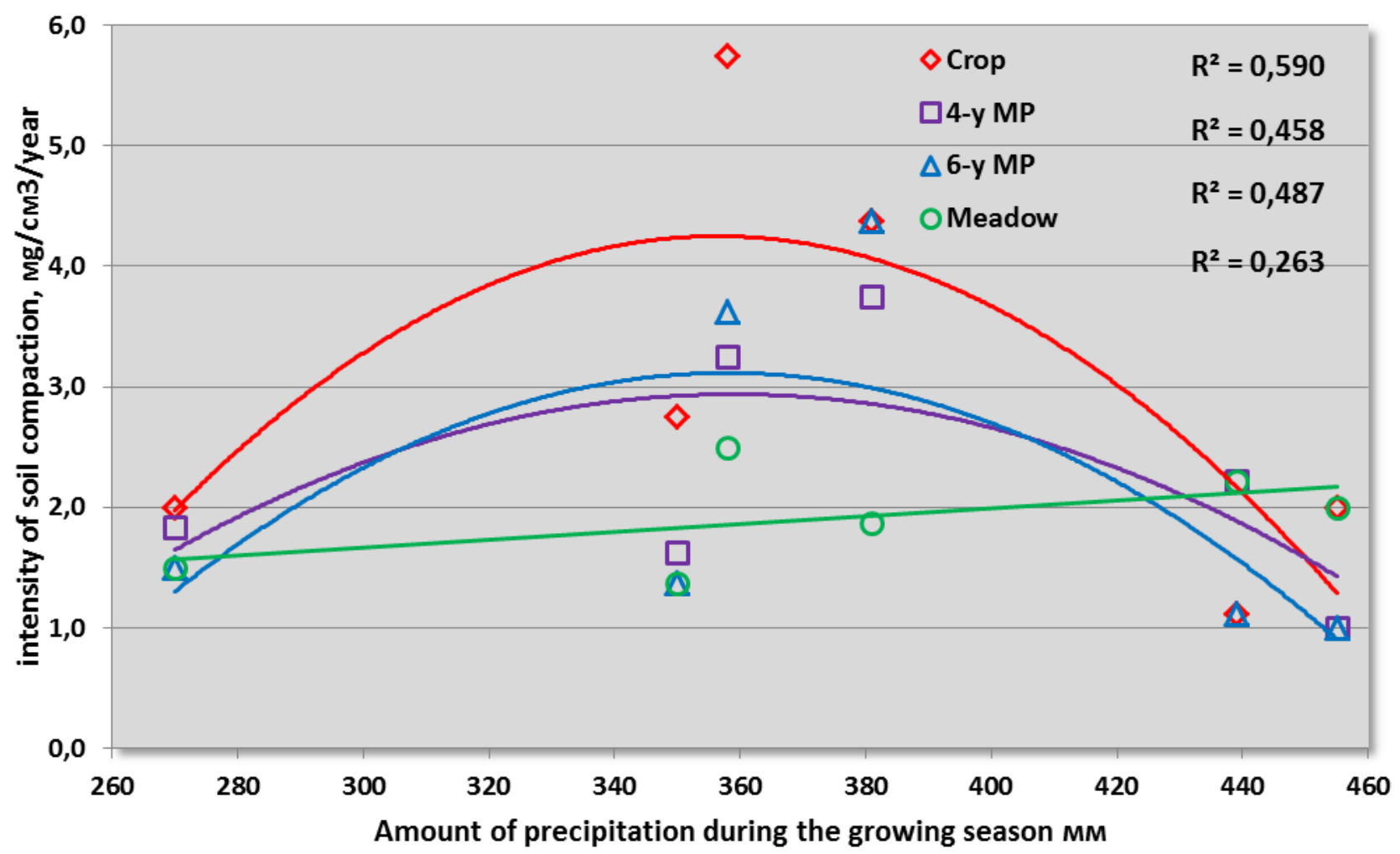

Fig 2 The influence of the conditions of use and the amount of precipitation during the growing season on the intensity of compaction of arable layer $(0-30 \mathrm{~cm})$ peat drained soil (array "Chemerne, Sarny research station, 1958-2015.)

As can be seen from the figure, the highest intensity of the triggering of peat organic matter occurs at $370-390 \mathrm{~mm}$ of precipitation during the vegetation period, which is close to normal and optimal for most plants. Obviously, this amount of precipitation is also optimal for the growth and activity of microflora soils, which contribute to the transformation of organic matter into its mineral components.

It should also be noted that under constant zaluzany soil, rainfall has much less influence on life processes of soil microorganisms than in crop rotations, where there is improved aeration.

Sarny research station for many decades, we also study the change of agrochemical properties of drained peat soils under the influence of drainage and long-term agricultural use in conditions of Western Polissya.

Monitoring of agrochemical indicators of the Central part corroborates array "Chemerne" hosting land Sarny research station are given in table 3 .

3. The influence of long-term agricultural utilization of peat soils on the content of total forms of nutrients (\% of dry soil)

\begin{tabular}{|c|c|c|c|c|c|}
\hline \multirow[b]{2}{*}{ Nutrients } & \multirow[b]{2}{*}{$\begin{array}{c}\text { Virgin soil } \\
\text { (data from } \\
\text { 1913) }\end{array}$} & \multicolumn{4}{|c|}{ The same cultivated plot } \\
\hline & & $\begin{array}{c}5 \text { years in culture } \\
\text { (data 1932) }\end{array}$ & $\begin{array}{c}45 \text { years in } \\
\text { culture } \\
\text { (data 1958) }\end{array}$ & $\begin{array}{c}88 \text { years in the } \\
\text { culture } \\
\text { (data 2001) }\end{array}$ & $\begin{array}{l}101 \text { years in } \\
\text { the culture } \\
\text { (data from } \\
\text { 2013) }\end{array}$ \\
\hline $\mathrm{N}$ & 3,25 & $3,44-3,65$ & 3,85 & 3,30 & 3,43 \\
\hline $\mathrm{P}_{2} \mathrm{O}_{5}$ & 1,42 & $0,88-1,22$ & 0,81 & 1,60 & 1,88 \\
\hline $\mathrm{K}_{2} \mathrm{O}$ & - & $0,05-0,15$ & $0,11-0,10$ & $0,08-0,10$ & $0,1-0,11$ \\
\hline $\mathrm{CaO}$ & 2,19 & 2,1 & 3,01 & - & 2,86 \\
\hline
\end{tabular}


Agrochemical studies suggest that long-term agricultural use has little effect on availability in the soil gross nitrogen and potassium showed only a significant increase in phosphorus. Thus, in comparison with virgin its number has increased in 2 times.

As can be seen from table 3, in peat drained lowland soil under the influence of drainage and long-term agricultural use, the content of total nitrogen over 45 years of agricultural use decreased by $0,05 \%$ on a completely dry soil, the content of it in 2001 made up 3,30\%, the content of total phosphorus increased by $0,79 \%$, total potassium content decreased to $0,11 \%$. The content of total nitrogen decreases with wear of peat organic matter and reduction of power peat soil layer.

During drainage and intensive agricultural use of the reaction of the soil-absorbing complex of drained peat soils is deteriorating - is the process of their intensive acidification.

4 The transformation parameters of acidity in the topsoil $(0-30 \mathrm{~cm})$ peat soil over a long period

\begin{tabular}{|l|l|l|}
\hline Year of studies & pH soil & Hr $\mathrm{mg} / \mathrm{eg}$, of $100 \mathrm{~g}$ of dry soil \\
\hline 1958 & 4,8 & 92,0 \\
\hline 1974 & 4,6 & 77,6 \\
\hline 1983 & 4,3 & 68,5 \\
\hline 1993 & 4,1 & 56,1 \\
\hline 2015 & 3,8 & 41,5 \\
\hline
\end{tabular}

The data in table 4 show that over 57 years of research, the acidity of the soil decreased by 1,0 , the value of hydrolytic acidity decreased by $51,5 \mathrm{mg} / \mathrm{EQ}$ per $100 \mathrm{~g}$ of soil.

Crop rotation, timely and quality cultivation of the soil, mineral fertilizers contribute to the formation and accumulation of peat organic matter and the decrease in the intensity of mineralization, i.e. decomposition it to simple compounds, capable of being easily leached with drainage water and pollute the environment. For 4 -year period of use the content of fulvic acids decreased by $9 \%$ and humic increased by $11 \%$, reflecting positive qualitative changes in organic matter of peat.

It is established that when the agricultural use of drained peat soils there is a change in its ash content (table 5)

5. The transformation of ash drained lowland hepnova-sedge peat drained soil under the influence of drainage and long-term agricultural use, \%.

\begin{tabular}{|l|c|c|c|c|c|c|}
\hline \multirow{2}{*}{ Rotation } & \multicolumn{6}{c|}{ Years of research } \\
\cline { 2 - 7 } & 1958 & 1974 & 1983 & 1993 & 2001 & 2015 \\
\hline Crop rotation & 14 & 17 & 19 & 23 & 29 & 35 \\
\hline Rotation with a 4-year meadow period & 16 & 20 & 22 & 24 & 26 & 28 \\
\hline Rotation with a 6-year meadow period & 14 & 17 & 19 & 22 & 24 & 26 \\
\hline Long-term meadow & 15 & 18 & 19 & 21 & 24 & 27 \\
\hline
\end{tabular}

For 57-year period of use of drained peat soils ash soils in posepny crop rotations has increased 2,8 times, from 14 to $35 \%$. The increase in ash meadows under long term usage from $15 \%$ to $27 \%$, in crop rotation with four fields of perennial grasses from 16 to $28 \%$, with six fields 14 to $26 \%$ (table 5). Therefore, the dynamics of mineralization of organic matter (increasing ash content of the soil) depended on the intensity of agricultural use (Fig. 3). So the rate of ashing of the organic matter of peat in posepny rotation to $3,79 \%$ for 10 years of use. Under long-term grassland dynamics the exposure of soil organic matter accounted for only $2,11 \%$ in 10 years. In crop rotations with 4-and 6-year-prosperous period, the dynamics of this process was close to a continuous alkali - and 2,12 2,22 \% in 10 years. 


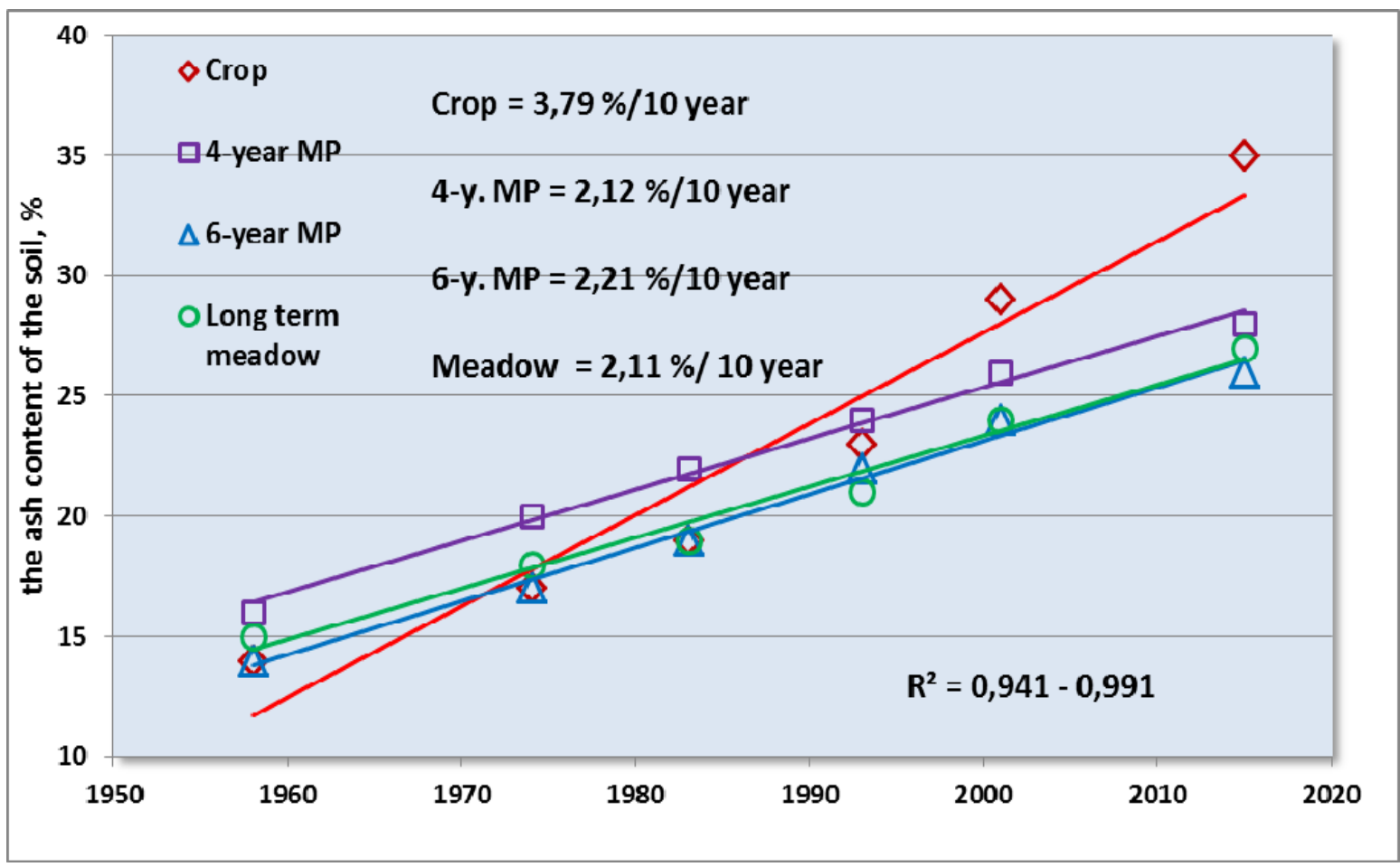

Fig 3. The change in the ash content of the arable layer $(0-30 \mathrm{~cm})$ peat drained soil under the influence of long agricultural use (array "Chemerne, Sarny research station, 1958-2015)

\section{Conclusions}

The article presents the results of years of studies on the transformation of water-physical and agrochemical properties of drained peat soils under long-term drainage and agricultural use. It was found that the intensity of the rows and agricultural use of peat soils affected by the change of water physical and agrochemical properties. So over many years of research of soil density on the long meadows increased 1,58 times $\left(1958-0,210 \mathrm{~g} / \mathrm{cm}^{3}, 2015-0,333 \mathrm{~g} / \mathrm{cm}^{3}\right)$, and under intense agricultural use (crops rotation) 2,10 times $\left(1958-0,210 \mathrm{~g} / \mathrm{cm}^{3}, 2015-0,446 \mathrm{~g} / \mathrm{cm}^{3}\right)$. It was found that for more than 50 years of agricultural use of peat soils and poorly medium ash transformed into multiplex).

\section{Bibliography}

1. Bambalow N.N. The balance of organic substance of peat soils and methods of its study. - Minsk: Science and technology, 1984. - $81 \mathrm{p}$.

2. Gimbargewskiy V.R., Slysiar I.T., Kowalenko T.M., Shmatok A.B., Chorna A.B. Agricultural use of drained lands in humid areas. Methodical recommendations. - Kiev. Agricultural science, 2000 $-75 \mathrm{p}$.

3. Zymenko T.G. Microbiological processes in melirovannyh peatbogs of Belarus and their directed regulation. - Minsk: Science and technology - 1977. - 208 p.

4. Zybets B.M., Dybrawa B.I. The change of water-physical properties of the peat during reclamation of wetlands. - Soil science, 1981. - № 4. - C. 79-85.

5. Ephimow B. N. Peat soils and their fertility. - Л.: Agropromizdat, 1986. -264 p.

6. Ryghyk C.N., Slusiar I.T. Agroecological foundations of effective use drained soils Polissya and foreststeppe of Ukraine // the Kiev agricultural science - 2006. - P. 135-146.

7. Starikow X.N. Wetting drained peatlands. - M: Kolos, 1977, -295 p.

8. Tryskawetskiy R.S. Peat soils and peatlands of the Ukraine. - Kharkiv, 2010. $-278 p$.

9. Shevchenko V.P., Shevchenko N.N., Gorodniy N,G. Theoretical and technological basis for drained reclamation agriculture // Kiev: Naukova Dumka, 1976. - 371 p.

10. Kowalski Z. Okreslanie murszow-torfowej. - Rocszniki nauk Rolniczych 1970, seria F., t.77, S 455-468. 